\title{
Relação entre percepção de justiça organizacional e satisfação no trabalho
}

\section{Resumo}

Objetivo: $\mathrm{O}$ estudo objetiva verificar a relação da percepção de justiça distributiva de recompensas, distributiva de tarefas, processual, interpessoal e informacional com a satisfação no trabalho.

Método: Pesquisa de levantamento foi realizada com funcionários de prestadoras de serviços contábeis, obtendo-se 140 questionários válidos. A percepção de justiça foi analisada nas perspectivas distributiva das recompensas, distributiva das tarefas, processual, interpessoal e informacional. A satisfação no trabalho foi analisada em relação aos colegas, salário, chefia, o trabalho em si e promoções.

Resultados: As correlações evidenciam fortes associações entre todas as dimensões de justiça. Os escores de percepção de justiça e de satisfação de alguns respondentes foram baixos, sendo que a maior percepção de justiça encontra-se na dimensão interpessoal, enquanto o maior nível de satisfação é com a chefia. As percepções de justiça e satisfação não foram afetadas por diferenças de gênero, idade, tempo de casa e metas. Entretanto, diferenças foram observadas no que concerne ao recebimento de remuneração variável.

Contribuições: $\mathrm{O}$ estudo contribui para o refinamento teórico, ao analisar associações entre cinco dimensões de justiça e cinco categorias da satisfação no trabalho. Geralmente as percepções de justiça são analisadas em apenas três dimensões principais e a satisfação no trabalho é capturada no seu aspecto geral.

Palavras-chave: Justiça distributiva; Justiça processual; Justiça interacional; Satisfação no trabalho.

\section{Ilse Maria Beuren}

Doutora em Controladoria e Contabilidade pela FEA/USP e Professora do Programa de Pós-Graduação em Contabilidade da Universidade Federal de Santa Catarina (UFSC). Contato: Universidade Federal de Santa Catarina, Campus Reitor João David Ferreira Lima, s/n, Bairro Trindade. Florianópolis (SC). CEP 88040-970.

E-mail: ilse.beuren@gmail.com

\section{Vanderlei dos Santos}

Doutorando em Contabilidade na Universidade Federal de Santa Catarina (UFSC) e Professor da Universidade do Estado de Santa Catarina (Udesc). Contato: Universidade Federal de Santa Catarina, Campus Reitor João David Ferreira Lima, $s / n$, Bairro Trindade. Florianópolis (SC). CEP 88040-970. E-mail: vanderleidossantos09@gmail.com

\section{Leandro Marques}

Mestre em Ciências Contábeis pela Universidade Regional de Blumenau (Furb) e Professor da Faculdade La Salle Lucas do Rio Verde. Contato: Avenida Universitária, 1000W. Lucas do Rio Verde (MT). CEP: 78455-000.

E-mail: leandromarques@hotmail.com

\section{Michel Resendes}

Bacharel em Ciências Contábeis pela Universidade do Estado de Santa Catarina (Udesc). Contato: Rua Dr. Getúlio Vargas, 2822 - Bairro Bela Vista. Ibirama (SC). CEP: 89140-000.

E-mail: michel_resendes@hotmail.com 


\section{Introdução}

A justiça organizacional desenvolveu-se como um conceito multidimensional, em que novas dimensões surgem com o desenvolvimento e aprofundamento de seus estudos (Ahmadi, Daraei, Rabiel, Salamzadeh \& Takallo, 2012). Todavia, ainda não há consenso entre os estudiosos do assunto sobre quais dimensões constituem o construto da justiça organizacional. Enquanto alguns estudiosos (Alexander \& Ruderman, 1987; McFarlin \& Sweeney, 1992; Martin \& Bennet, 1996) consideram apenas duas dimensões, outros apontam três (Goldman, 2003), quatro (Colquitt, Conlon, Wesson, Porter \& Ng, 2001; Souto \& Rego, 2003; Rego \& Souto, 2004) e até cinco dimensões (Rego, 2000; Rego, 2001; Rego, 2002).

As duas primeiras dimensões que foram foco dos estudiosos da área organizacional compreendem a justiça distributiva, desenvolvida a partir dos estudos de Adams (1965), e a justiça processual, introduzida por Thibaut e Walker (1975). Posteriormente, com o estudo de Bies e Moag (1986) surge a terceira dimensão da justiça organizacional, denominada "justiça interacional". Estudos contemporâneos aos de Bies e Moag (1986), como de Greenberg (1993a) e Colquitt et al. (2001), suscitaram a divisão da justiça interacional em duas dimensões, a justiça interpessoal e a justiça informacional. Posteriormente, Rego (2000) forneceu evidências empíricas de uma quinta dimensão: a justiça distributiva das tarefas.

Porém, independente do número de dimensões consideradas, as organizações atualmente estão preocupadas com o modo como seus empregados experimentam a justiça, não só no que se refere às recompensas que eles recebem da relação de emprego, mas também do modo como são tratados pelo sistema organizacional e por seus agentes (Lamertz, 2002). Essa preocupação, em parte, deve-se ao fato de que a literatura vem demonstrando que níveis mais elevados de percepções de justiça estão, de forma geral, associados a comportamentos mais positivos no local de trabalho (Rahim, Magner \& Shapiro, 2000).

Apesar de o objetivo final (o resultado econômico-financeiro) continuar o mesmo, a forma como as organizações buscam atingir tais resultados vem se alterando com o passar do tempo. Percebeu-se que a maximização dos lucros não tem origem apenas em melhores políticas de vendas ou redução de custos, mas passou-se também a considerar o bem-estar dos indivíduos responsáveis pelas atividades da organização, disponibilizando a eles ambientes de trabalho mais agradáveis e mais justos.

Nessa perspectiva, a satisfação dos funcionários torna-se um aspecto relevante para a organização, já que cada vez mais tem-se demonstrado que rentabilidade, produtividade, retenção de funcionários e satisfação de clientes estão associados a níveis de satisfação do empregado, pois funcionários satisfeitos e motivados irão gerar maior empatia e satisfação no cliente, o que se refletirá positivamente no desempenho organizacional (Lai Wan, 2007). Em função das consequências que a satisfação pode exercer sobre o trabalhador e seu desempenho, a satisfação no ambiente de trabalho tornou-se um fenômeno amplamente estudado por estudiosos do mundo inteiro (Martinez \& Paraguay, 2003).

Diversos estudos foram realizados nos mais variados ambientes e situações sobre o impacto da justiça organizacional no nível de satisfação dos trabalhadores. Na literatura internacional, podem-se citar as investigações conduzidas com funcionários do Governo federal dos EUA (Alexander \& Ruderman, 1987), funcionários de empresas privadas (McFarlin \& Sweeney, 1992), funcionários e professores de universidades (Firoozi, Kazemi \& Sayadi, 2017), rede hoteleira (López-Cabarcos, Pinho \& Rodríguez, 2015), além de meta-análises (Cohen-Charash \& Spector, 2001; Colquitt et al., 2001). A literatura nacional é menos abundante de trabalhos que tratam dos reflexos da justiça organizacional sobre a satisfação no trabalho. Dentre os poucos estudos identificados, destaca-se o de Dal Vesco, Popik e Beuren (2016), realizado com funcionários de uma cooperativa.

Entretanto, não foram identificados estudos que abordaram essa temática contemplando funcionários de prestadoras de serviços contábeis. Parker e Kohlmeyer (2005) examinaram o papel da justiça organizacional na decisão do funcionário de deixar uma empresa de contabilidade pública. Os resultados do levantamento com 76 contadores apontaram que as percepções de equidade influenciam as intenções turnover por meio do compromisso organizacional e da satisfação no trabalho. Os autores investigaram apenas a justiça distributiva, e a satisfação no trabalho foi aferida no seu aspecto geral. 
Assim tem-se a seguinte questão de pesquisa: Qual a relação entre a percepção de justiça organizacional e a satisfação no trabalho de funcionários de prestadoras de serviços contábeis? Desse modo, o objetivo principal do estudo é verificar a relação da percepção de justiça distributiva de recompensas, distributiva de tarefas, processual, interpessoal e informacional com a satisfação no trabalho. O campo investigado é o de prestadoras de serviços contábeis, que apresentam um ambiente de trabalho propício ao estresse, pois exige atenção dos indivíduos na realização das atividades e frequente atualização quanto às legislações societária, fiscal e trabalhista. A relação entre as pessoas é intensa, com colegas de trabalho, superiores e clientes. Das tensões e processos organizacionais inerentes ao trabalho, podem emergir sentimentos de injustiça/justiça, que se refletem na satisfação dos indivíduos.

De modo complementar, o estudo objetiva avaliar se determinadas características (gênero, idade, tempo de empresa, existência de metas de trabalho e adoção da sistemática de remuneração variável) implicam diferenças significativas de percepções de justiça e satisfação no trabalho. Pesquisas, como de Sweeney e McFarlin (1997) e Choi (2010), apontam que características dos indivíduos podem explicar diferentes percepções de justiça. Sweeney e McFarlin (1997) preconizam que as mulheres tendem a enfatizar os procedimentos justos e as relações interpessoais, ao contrário dos homens, que geralmente enfatizam a justiça distributiva. Portanto, essa análise pode ser útil, por exemplo, no estabelecimento de metas, na concessão de remuneração variável, nas relações interpessoais, uma vez que podem suscitar diferentes sentimentos de justiça e satisfação no trabalho.

Chetty e Neeraja (2017) advertem que a satisfação no trabalho se reflete em outros resultados organizacionais, como compromisso organizacional, comportamento de cidadania organizacional e eficácia gerencial, entre outros, sendo que as percepções de justiça se constituem em importante preditor da satisfação no trabalho. Assim, é pertinente a investigação de quais percepções de justiça estão associadas a dimensões específicas da satisfação no trabalho. Nesse sentido, este estudo justifica-se, na perspectiva teórica, por fornecer evidências do relacionamento das dimensões da justiça organizacional com a satisfação no trabalho, contribuindo assim para o arcabouço teórico.

De acordo com Assmar, Ferreira e Souto (2005), os estudos nacionais sobre justiça organizacional são esparsos. Nesse sentido, este estudo vem encorpar a literatura nacional sobre o tema, fornecendo evidências sobre o papel da justiça organizacional no ambiente de trabalho, no caso, de prestadoras de serviços contábeis. O entendimento de como a justiça se relaciona com a satisfação dos trabalhadores pode contribuir para a melhoria das relações entre as organizações e seus funcionários, refletindo-se sobre sua satisfação e desempenho. Cabe ainda destacar que a maioria dos estudos não contemplaram dimensões específicas da satisfação no trabalho, além de não contemplar a justiça das tarefas, o que pode oferecer insights para futuras pesquisas.

\section{Referencial Teórico}

\subsection{Justiça organizacional}

A justiça organizacional pode ser entendida como a psicologia da justiça aplicada ao ambiente organizacional, focalizando-se nas percepções de justiça existentes nas relações entre trabalhadores e suas organizações (Assmar, Ferreira, \& Souto, 2005). Para Omar, Ferreira, Souto, Delgado, Assmar, González e Galáz (2007), o conceito de justiça organizacional está relacionado às percepções que os funcionários têm sobre o que é certo ou errado dentro das organizações a que pertencem.

Greenberg (1993b) aduz que as pessoas se comportarão altruisticamente para com a organização em que trabalham, se acreditarem que estão sendo tratadas de forma justa. Essa crença contribuirá para que mantenham atitudes positivas em relação ao trabalho, aos supervisores e à organização, como, por exemplo, acatar as decisões dos superiores, evitar comportamentos antissociais, além de apresentarem comprometimento e qualidade no trabalho, satisfação profissional, saúde e bem-estar (Tepper, 2001). Por 
outro lado, quando consideram que estão sendo tratados de forma injusta, tal pode gerar sentimentos de raiva, insatisfação e desmotivação, o que resulta em queda na produtividade e na qualidade do trabalho e absenteísmo (Omar et al., 2007).

Pesquisas sobre justiça organizacional evoluíram sob diferentes dimensões ao longo dos anos. Para Klendauer e Deller (2009), a justiça organizacional é analisada a partir de três dimensões: justiça distributiva, justiça processual e justiça interacional. Por sua vez, Colquitt (2001) propõe desmembrar a justiça interacional em duas dimensões distintas: justiça interpessoal e justiça informacional. Rego (2000), ao investigar a temática de justiça organizacional, contemplou uma quinta dimensão: a justiça das tarefas, sendo esta uma divisão da justiça distributiva.

A justiça distributiva é definida como a justiça dos resultados, como salários, recompensas, promoções, lucros distribuídos aos trabalhadores, classificação obtida na avaliação de desempenho. A sua abordagem está pautada na teoria da Equidade, segundo a qual os indivíduos tendem a avaliar a justiça distributiva a partir da proporcionalidade entre os resultados (outcomes) e o esforço necessário para consegui-lo (inputs), comparando seus resultados com os de outros indivíduos (Adams, 1965). Caso a percepção seja de que os rácios são iguais e de que há igualdade, haverá sentimentos de satisfação e de justiça, o que aumentará a satisfação no trabalho e a intenção de permanecer na organização (Colquitt et al., 2001; Souto \& Rego, 2003; Langevin \& Mendoza, 2013).

A justiça processual compreende as percepções de justiça relativas aos procedimentos usados nos sistemas de avaliação de desempenho, nos acréscimos salariais e de promoções, nos processos de recrutamento e seleção, de alocação de recursos (Leventhal, 1980; Souto \& Rego, 2003; Sotomayor, 2007). A justiça processual considera os métodos, mecanismos, meios e processos utilizados nas determinações dos resultados (Cohen-Charash \& Spector, 2001). Leventhal (1980) estabeleceu seis regras procedimentais que indicam se determinado procedimento é percebido, ou não, como justo pelos indivíduos: consistência, ausência de vieses e interesses pessoais, exatidão da informação, correção (ou mecanismos de correção/recurso), representatividade dos envolvidos nos processos e ética.

Em contraste com a justiça distributiva, que está relacionada com um resultado específico, como o pagamento, a justiça processual é mais relacionada com os resultados organizacionais, como compromisso organizacional e comportamentos de cidadania organizacional (Masterson, Lewis, Goldman \& Taylor, 2000; Cohen-Charash \& Spector, 2001; Colquitt et al., 2001). Greenberg (1987) atribui maior força à justiça processual do que à justiça distributiva, uma vez que, quando os procedimentos são percebidos como justos, os trabalhadores ficam menos preocupados com os resultados injustos e tendem a considerar justo o que é injusto, apresentando comportamentos positivos.

A terceira dimensão é a justiça interacional, que se concentra na qualidade do tratamento interpessoal pela organização, ou à forma como a gestão comporta-se em relação ao beneficiário da justiça (Cohen-Charash \& Spector, 2001; Colquitt et al. 2001). Refere-se ao tratamento interpessoal ou ao nível de equidade percebido na forma como os funcionários são tratados na organização. A justiça interacional abrange os comportamentos dos gestores para os subordinados, como o grau de honestidade, sensibilidade e respeito demonstrado durante a interação. Em contraste à justiça processual, em que as percepções de injustiça são em relação à organização, as percepções de injustiça interacional são dirigidas ao superior (Masterson et al., 2000).

Greenberg (1993a) propôs o desdobramento da justiça interacional em duas dimensões (a justiça interpessoal e a justiça informacional), introduzindo, dessa forma, um modelo de quatro dimensões para a justiça organizacional. Para Colquitt et al. (2001), a justiça interpessoal reflete o grau com que as pessoas são tratadas com cortesia, dignidade e respeito pelas autoridades ou pelas partes envolvidas na execução dos procedimentos ou na determinação dos resultados. Assim, espera-se que um tratamento justo eleve as percepções de justiça, aumente o grau de aceitação das decisões e provoque reações positivas (Greenberg, 1993a), ao passo que a justiça informacional focaliza nas explicações fornecidas às pessoas, sobre o porquê de os procedimentos terem sido utilizados de certa maneira ou o porquê de os resultados terem sido distribuídos de certo modo (Colquitt et al., 2001). Dessa forma, presume-se que as explica- 
ções e justificativas tornam as decisões mais transparentes, contribuindo para mitigar reações negativas quando da percepção de injustiças e para minimizar respostas adversas aos resultados desfavoráveis obtidos (Greenberg, 1993a).

Rego (2000), ao realizar a validação de um instrumento de medida das percepções de justiça organizacional, demonstrou ser a justiça melhor conceituada com cinco dimensões. Na pesquisa conduzida pelo autor, a justiça distributiva apresentou-se dividida em duas dimensões independentes, sendo que a nova dimensão foi denominada "justiça distributiva das tarefas". Assim, enquanto a justiça distributiva centra-se na distribuição das recompensas, a dimensão identificada por Rego (2000) refere-se à distribuição e à alocação de tarefas, da carga de trabalho e das responsabilidades no ambiente de trabalho.

Não é consensual entre os pesquisadores a distinção entre justiça processual e justiça interacional, tampouco a divisão dessa última em interpessoal e informacional (Beuren, Klein, Lara, \& Almeida, 2016). Contudo, Konovsky (2000) recomenda a diferenciação visto que há literatura suficiente, demonstrando que as três dimensões (processual, interpessoal e informacional) são tipos únicos de justiça. Estudos, como os de Colquitt (2001), Colquitt et al. (2001), Rego (2001), Souto e Rego (2003) e Rego e Souto (2004), apresentam evidências empíricas de que a divisão da justiça interacional é pertinente, uma vez que a justiça interpessoal afeta outcomes organizacionais diferentes da justiça informacional.

Nesse estudo optou-se por utilizar o modelo com cinco dimensões da justiça organizacional, a fim de, inclusive, verificar se as várias dimensões são relacionadas entre si. Optou-se também em contemplar a justiça das tarefas, pouco investigada nos estudos, e conceitualmente é aplicável aos funcionários de prestadoras de serviços contábeis.

\subsection{Satisfação no trabalho}

A satisfação no trabalho vem despertando o interesse de estudiosos de diversas áreas, desde a década de 1930. Esse interesse decorre da influência que a satisfação pode exercer sobre o trabalhador, afetando sua saúde física e mental, suas atitudes e seu comportamento profissional e social (Martinez \& Paraguay, 2003).

Inicialmente a satisfação no trabalho foi associada à motivação e, por muitas vezes, incorretamente com ela confundida. Estudiosos dessa abordagem consideravam a satisfação no trabalho como um componente da motivação que levava os trabalhadores a apresentarem indicadores de comportamento favoráveis, como aumento no desempenho e na produtividade, permanência na empresa e redução de faltas ao trabalho. Desta corrente surgiram teorias, como a da Motivação-Higiene e a da Satisfação das Necessidades (Siqueira, 2008).

Porém, mesmo decorridos mais de 80 anos de pesquisa sobre o assunto, ainda não há consenso sobre conceitos, teorias ou modelos teóricos sobre a satisfação no trabalho. Essa dificuldade em se estabelecer uma definição comum deve-se, em parte, ao fato de que a satisfação no trabalho é um fenômeno subjetivo, que pode variar de pessoa para pessoa, de circunstância para circunstância e estar sujeita a influências internas e externas ao ambiente de trabalho (Martinez \& Paraguay, 2003).

Entre os anos de 1970 e 1980, o conceito de satisfação passou a ser concebido pelos estudiosos do comportamento humano como uma atitude. Dessa forma, Robbins (2005, p. 61) definiu a satisfação no trabalho como "a atitude geral de uma pessoa em relação ao trabalho que ela realiza". Neste período, a satisfação era tida como um fator capaz de predizer diferentes comportamentos de trabalho, como produtividade, desempenho, rotatividade e absenteísmo (Siqueira, 2008).

Outra vertente de estudos sobre a satisfação no trabalho passou a considerá-la como um estado emocional. Locke (1969) entendia a satisfação no trabalho como um estado emocional agradável resultante da avaliação que o indivíduo faz de seu trabalho. Siqueira (2008) adverte que a satisfação no trabalho adentra o século XXI como um múltiplo conceito que aborda a afetividade no ambiente de trabalho, constituindo-se em um vínculo afetivo do indivíduo com seu trabalho. 
Apesar dessas diferentes concepções, as dimensões constitutivas da satisfação no trabalho sofreram poucas modificações com o passar dos anos. Dentre elas, as dimensões que conseguiram manter-se ao longo das décadas foram a satisfação com os salários, satisfação com os colegas de trabalho, satisfação com a chefia, satisfação com as promoções e com o próprio trabalho. Considerando a satisfação no trabalho como as experiências prazerosas que o indivíduo vivencia no ambiente de trabalho, cada uma das cinco dimensões representa uma fonte de tais experiências (Siqueira, 2008).

Nesse sentido, Siqueira (2008) apresenta a Escala de Satisfação no Trabalho (EST) composta por 25 itens, cujo objetivo é medir o grau de contentamento do trabalhador em relação ao seu trabalho. A EST foi criada e validada no Brasil e baseia-se em uma visão multidimensional de satisfação no trabalho, sendo que seus itens cobrem as cinco dimensões teóricas, conforme demonstrado na Figura 1.

\begin{tabular}{ll}
\hline \multicolumn{1}{c}{ Dimensões } & \multicolumn{1}{c}{ Definições } \\
\hline Satisfação com o salário & $\begin{array}{l}\text { Contentamento com o que recebe como salário se comparado com o quanto o indivíduo } \\
\text { trabalha, com sua capacidade profissional, com o custo de vida e com os esforços feitos na } \\
\text { realização do trabalho. }\end{array}$ \\
\hline $\begin{array}{l}\text { Satisfação com os } \\
\text { colegas de trabalho }\end{array}$ & $\begin{array}{l}\text { Contentamento com a colaboração, a amizade, a confiança e o relacionamento mantido com } \\
\text { os colegas de trabalho. }\end{array}$ \\
\hline Satisfação com a chefia & $\begin{array}{l}\text { Contentamento com a organização e capacidade profissional do chefe, com o seu interesse } \\
\text { pelo trabalho dos subordinados e entendimento entre eles. }\end{array}$ \\
\hline $\begin{array}{l}\text { Satisfação com as } \\
\text { promoções }\end{array}$ & $\begin{array}{l}\text { Contentamento com o número de vezes que já recebeu promoções, com as garantias } \\
\text { oferecidas a quem é promovido, com a maneira da empresa realizar promoções e com o } \\
\text { tempo de espera pela promoção. }\end{array}$ \\
\hline $\begin{array}{l}\text { Satisfação com a } \\
\text { natureza do trabalho }\end{array}$ & $\begin{array}{l}\text { Contentamento com o interesse despertado pelas tarefas, com a capacidade de absorverem } \\
\text { o trabalhador e com a sua variedade. }\end{array}$ \\
\hline
\end{tabular}

Figura 1. Dimensões da satisfação no trabalho

Fonte: adaptada de Siqueira (2008).

Nesse estudo foi utilizada a EST desenvolvida por Siquera (2008) para avaliar a satisfação de funcionários das prestadoras de serviços contábeis. Este instrumento já foi utilizado e validado nas pesquisas realizadas por Suehiro, Santos, Hatamoto e Cardoso (2008) e Rueda, Baptista, Souza e Degenhardt (2010).

Pesquisas vêm sendo realizadas com o intuito de identificar quais os fatores poderiam ser desencadeadores de níveis de satisfação ou insatisfação no trabalho. A percepção de justiça organizacional pode afetar os níveis de satisfação no trabalho. Desse modo, relacionam-se a seguir alguns estudos e suas descobertas em relação à percepção de justiça organizacional versus satisfação no ambiente de trabalho.

\subsection{Relação entre justiça organizacional e satisfação no trabalho}

A percepção de justiça organizacional pode exercer impacto sobre a satisfação dos trabalhadores. Nesse sentido, diversos pesquisadores têm realizado estudos para verificar a relação existente entre justiça organizacional e satisfação no trabalho. McFarlin e Sweeney (1992) realizaram um estudo com 675 bancários e constataram que tanto a justiça processual quanto a justiça distributiva relacionam-se de forma significativa com a satisfação no trabalho. Martin e Bennet (1996) chegaram a resultados similares ao conduzirem uma pesquisa com 1.377 empregados de uma companhia de serviços financeiros.

Aryee, Budhwar e Chen (2002), ao pesquisarem empregados de uma organização pública indiana, encontraram efeitos indiretos da justiça processual e interacional sobre a satisfação no trabalho e efeitos diretos e indiretos da justiça distributiva sobre ela. Choi (2011), ao conduzir um estudo com empregados de 24 departamentos governamentais dos EUA, descobriu que altos níveis de justiça (distributiva, processual e interacional) estão positivamente relacionados com satisfação no trabalho. Ahmadi et al. (2012) chegaram às mesmas conclusões ao investigarem empregados e gerentes de duas grandes fábricas do Irã. 
Dal Vesco, Popik e Beuren (2016) encontraram relação significativa entre as dimensões distributiva e interacional e a satisfação no trabalho de 110 empregados de uma cooperativa de produção. Porém, não constataram o mesmo efeito em relação à justiça processual. Colquitt et al. (2001) realizaram uma revisão meta-analítica de 183 estudos sobre justiça organizacional e constataram que as dimensões distributiva e processual da justiça organizacional encontram-se altamente relacionadas à satisfação no trabalho, enquanto as dimensões interpessoal e informacional encontram-se moderadamente relacionadas à satisfação no trabalho. Desse modo, elaborou-se a primeira hipótese do estudo:

- H1: Percepções de justiça distributiva, processual, interpessoal, informacional e de tarefas estão positivamente relacionadas com a satisfação no trabalho.

A confirmação da hipótese $\mathrm{H} 1$ indicará que quando os indivíduos percebem maior sentimento de justiça nas atividades laborais, terão maior satisfação no trabalho. Espera-se com esta hipótese que os resultados sejam similares aos de Colquitt et al. (2001).

McFarlin e Sweeney (1992) e Martin e Bennet (1996) observaram em seus estudos que a dimensão distributiva é a mais forte preditora da satisfação no trabalho. Os resultados da pesquisa realizada por Choi (2011) também revelaram que a dimensão distributiva da justiça organizacional é mais fortemente associada à satisfação no trabalho do que as demais dimensões. Nadiri e Tanova (2010) observaram que a justiça distributiva é mais forte preditora da satisfação no trabalho do que as dimensões processual e interacional. Assim, elaborou-se a segunda hipótese da pesquisa:

- H2: A percepção de justiça distributiva está mais fortemente relacionada à satisfação no trabalho do que as demais dimensões da justiça organizacional.

Em oposição aos resultados apresentados, Alexander e Ruderman (1987) identificaram a justiça processual como mais forte preditora da satisfação no trabalho do que a justiça distributiva. Tal pesquisa foi realizada com 2.800 funcionários do governo dos Estados Unidos. Warner, Reynolds e Roman (2005) constataram que a justiça distributiva nunca é mais forte preditora da satisfação no trabalho do que a justiça processual. Essas divergências podem ter ocorrido por conta da amostra utilizada.

A confirmação da hipótese $\mathrm{H} 2$ indicará que a justiça dos fins está mais relacionada com a satisfação no trabalho, convergindo com os resultados de McFarlin e Sweeney (1992), Martin e Bennet (1996) e Choi (2011), mas divergindo dos resultados de Alexander e Ruderman (1987) e Warner, Reynolds e Roman (2005).

Outros estudos demonstraram que diferentes dimensões da justiça organizacional podem ser preditoras de determinadas dimensões da satisfação no trabalho. DeConinck e Stilwell (2004) verificaram que a justiça processual é uma importante preditora da satisfação com o supervisor, enquanto a justiça distributiva é uma forte preditora da satisfação com o pagamento. Zainalipour, Fini e Mirkamali (2010) encontraram correlação positiva entre as três dimensões da justiça organizacional (distributiva, processual e interacional) com a satisfação com a supervisão (chefia), colegas de trabalho, pagamento e promoções.

Os autores também verificaram correlação positiva entre satisfação com o crescimento, o status e as condições de trabalho com as dimensões informacional, processual e distributiva. A partir dos resultados destes estudos e das características de cada dimensão de justiça, acredita-se que determinadas dimensões de justiça estão mais relacionadas a um tipo específico de satisfação no trabalho, como a justiça distributiva e a satisfação com o salário e as promoções. Tal suposição deve-se ao fato de que cada dimensão de justiça afeta resultados organizacionais específicos (Masterson et al., 2000). 


\section{Metodologia da Pesquisa}

\subsection{População e amostra}

Um questionário foi enviado pelo Google Docs aos funcionários de 30 empresas prestadoras de serviços contábeis de cidades da região norte do Estado de Santa Catarina, escolhidas intencionalmente. A escolha das cidades se deu em função do acesso dos pesquisadores aos contatos necessários para realizar a survey. Optou-se pela distribuição dos instrumentos de pesquisas aos maiores escritórios de contabilidade das cidades escolhidas.

Houve retorno de 167 questionários respondidos, dos quais 27 apresentaram problemas, alguns com ausência de respostas e outros com duas respostas para a mesma assertiva. Esses foram eliminados, restando 140 questionários válidos para análise. O perfil dos respondentes compreendeu gênero, idade, formação acadêmica, área de formação, tempo de empresa, setor em que atua, função, tempo que exerce a função, metas formais e recebimento de remuneração variável.

A maioria dos respondentes (70,71\%) é do gênero feminino. Em relação à idade, a maioria $(82,14 \%)$ está na faixa entre 16 e 30 anos. Quanto ao nível de escolaridade, há uma grande quantidade de respondentes com ensino superior incompleto (45\%), mas também é grande o número de respondentes que possuem graduação completa e pós-graduação lato sensu (44,29\%). Entre os respondentes com ensino superior completo, o curso de Ciências Contábeis destaca-se com 72,22\%. Entre os que possuem curso de especialização, a maioria é na área de Gestão Tributária (34,62\%), seguida por Contabilidade (23,08\%) e Controladoria e Finanças (15,38\%).

No que concerne ao tempo de empresa, mais da metade $(52,86 \%)$ dos respondentes trabalham na empresa entre 1 a 5 anos. O número de respondentes que está há menos de um ano na empresa também é considerável (27,86\%), já o número de funcionários com mais de 10 anos é reduzido $(7,14 \%)$. Isso sugere rotatividade de pessoas, o que pode sinalizar falta de percepção de justiça e satisfação no trabalho.

Entre os respondentes, $26,43 \%$ atuam no setor contábil, $15,71 \%$ no setor fiscal, $13,57 \%$ no setor pessoal, enquanto a maioria $(33,57 \%)$ atua em mais de um setor. Em relação à função desempenhada, destacam-se auxiliar contábil (17,14\%), auxiliar fiscal-contábil (15\%) e auxiliar fiscal (11,43\%). Também houve respondentes que desempenham a função de coordenador ou gerente de setor $(7,86 \%)$ e de contador $(7,86 \%)$. No que se refere ao tempo na atual função, destaca-se a faixa de 1 a 5 anos, que concentrou $55 \%$ das respostas, seguida da faixa de até 1 ano, com $30,71 \%$ das respostas.

Quanto às metas, $72,14 \%$ dos respondentes trabalham com metas formais preestabelecidas. Porém, o número dos que possuem remuneração variável é pouco expressivo, totalizando $18,57 \%$ da amostra analisada. 


\subsection{Instrumento de pesquisa e procedimentos de análise dos dados}

A percepção de justiça organizacional e a satisfação no trabalho de funcionários de prestadoras de serviços contábeis foram mensuradas, utilizando-se das variáveis expostas no construto da pesquisa, conforme demonstrado na Figura 2.

\begin{tabular}{|c|c|c|c|}
\hline Variáveis & Dimensões & Finalidade & Aferição \\
\hline $\begin{array}{l}\text { Justiça organizacional } \\
\text { (Rego, 2001) }\end{array}$ & $\begin{array}{l}\text { Justiça distributiva } \\
\text { Justiça processual } \\
\text { Justiça interpessoal } \\
\text { Justiça informacional } \\
\text { Justiça distributiva de } \\
\text { tarefas }\end{array}$ & $\begin{array}{l}\text { Identificar a percepção } \\
\text { de justiça organizacional } \\
\text { nas relações de trabalho } \\
\text { de colaboradores de } \\
\text { prestadoras de serviços } \\
\text { contábeis. }\end{array}$ & $\begin{array}{l}\text { Foram expostas } 30 \text { assertivas, } \\
\text { sendo } 6 \text { para cada dimensão } \\
\text { de justiça, em uma escala de } \\
1 \text { a } 7 \text {, em que } 7 \text { indicava alta } \\
\text { percepção de justiça e } 1 \text { baixa } \\
\text { percepção de justiça e/ou } \\
\text { sentimento de injustiça. }\end{array}$ \\
\hline $\begin{array}{l}\text { Satisfação no trabalho } \\
\text { (Siqueira, 2008) }\end{array}$ & $\begin{array}{l}\text { Satisfação com salário } \\
\text { Satisfação com colegas } \\
\text { Satisfação com a chefia } \\
\text { Satisfação com promoções } \\
\text { Satisfação com a natureza } \\
\text { do trabalho }\end{array}$ & $\begin{array}{l}\text { Verificar o nível de } \\
\text { satisfação no trabalho } \\
\text { dos colaboradores de } \\
\text { prestadoras de serviços } \\
\text { contábeis }\end{array}$ & $\begin{array}{l}\text { Foram expostas } 25 \text { assertivas, } \\
\text { sendo } 5 \text { para cada dimensão da } \\
\text { satisfação, em uma escala de } \\
1 \text { a } 7 \text {, em que } 1 \text { representava } \\
\text { total insatisfação e } 7 \\
\text { representava total satisfação. }\end{array}$ \\
\hline
\end{tabular}

Figura 2. Construto da pesquisa

Fonte: elaboração própria.

O questionário foi estruturado em três blocos, direcionados aos funcionários de prestadoras de serviços contábeis. O primeiro bloco objetivou identificar o nível de satisfação dos funcionários; já o segundo bloco destinou-se à aferição da percepção de justiça organizacional dos respondentes; o último bloco capturava o perfil dos respondentes da pesquisa. As assertivas foram extraídas dos estudos de Rego (2001) e Siqueira (2008).

Antes de levar o questionário a campo, foi aplicada uma versão como pré-teste, com o intuito de averiguar possíveis problemas que poderiam ser percebidos pelos respondentes. Responderam ao pré-teste 10 pessoas que trabalham em empresas prestadoras de serviços contábeis, sendo que nenhuma dessas pessoas fizeram parte da amostra. Na aplicação do pré-teste, foram indicadas algumas alterações na redação do questionário.

$\mathrm{Na}$ análise dos dados, utilizaram-se técnicas de estatística descritiva, correlação de Pearson e os testes de medianas não paramétricos de Mann-Whitney e de Kruskal-Wallis. Na estatística descritiva, determinaram-se o mínimo e máximo, médias, desvio-padrão e coeficiente de variação das variáveis. A correlação de Pearson aplicou-se para verificar se há associação coerente e sistemática entre as variáveis observadas, e a força da associação de tais variáveis. Analisou-se a relação/associação entre todas as dimensões de justiça organizacional e todas as dimensões de satisfação no trabalho.

Por fim, visando atender ao objetivo complementar, os testes de Mann-Whitney e Kruskal-Wallis foram aplicados para avaliar se as características de gênero, idade, tempo de empresa, existência de metas de trabalho e adoção da sistemática de remuneração variável implicam diferenças de percepção de justiça e satisfação no trabalho. Nesse sentido, foram comparadas as percepções de justiça e satisfação no trabalho de cinco grupos principais: (i) gênero: masculino versus feminino; (ii) metas no trabalho, se os respondentes possuíam, ou não, metas preestabelecidas; (iii) remuneração variável, se a sistemática de remuneração variável está instituída, ou não, nas organizações dos respondentes; (iv) idade dos respondentes, cuja divisão foi realizada em três grupos: até 25 anos, de 26 a 30 anos, acima de 30 anos; e (v) tempo de empresa, até um ano, de um a cinco anos, acima de 5 anos. O teste de Mann-Whitney $U$ foi utilizado para analisar as diferenças nos três primeiros grupos (gênero, metas no trabalho e remuneração variável), ao passo que o teste Kruskal-Wallis foi aplicado para analisar diferenças nos grupos de idade e tempo de empresa. 


\section{Descrição e Análise dos Dados}

\subsection{Estatísticas descritivas}

Na Tabela 1, apresentam-se dados relativos à estatística descritiva aplicada em cada variável contida no construto da pesquisa. Foram determinados o mínimo e máximo, as médias, desvio-padrão e o coeficiente de variação das variáveis investigadas.

Tabela 1

Estatísticas descritivas das variáveis

\begin{tabular}{lccccc}
\hline \multicolumn{1}{c}{ Variáveis } & Mínimo & Máximo & Média & Desvio-Padrão & Coeficiente de variação \\
\hline Justiça distributiva de recompensas & 1 & 7 & 4,55 & 1,83 & 40,29 \\
\hline Justiça distributiva de tarefas & 1 & 7 & 5,38 & 1,53 & 28,41 \\
\hline Justiça processual & 1 & 7 & 4,79 & 1,68 & 35,06 \\
\hline Justiça interacional interpessoal & 1 & 7 & 5,55 & 1,53 & 27,51 \\
\hline Justiça interacional informacional & 1 & 7 & 5,02 & 1,70 & 33,93 \\
\hline Satisfação com o salário & 1 & 7 & 4,39 & 1,67 & 38,05 \\
\hline Satisfação com os colegas de trabalho & 1 & 7 & 5,50 & 1,24 & 22,50 \\
\hline Satisfação com a chefia & 1 & 7 & 5,65 & 1,41 & 24,97 \\
\hline Satisfação com as promoçães & 1 & 7 & 4,25 & 1,86 & 43,80 \\
\hline Satisfação com a natureza do trabalho & 1 & 7 & 5,33 & 1,30 & 24,31 \\
\hline
\end{tabular}

Fonte: dados da pesquisa.

Pela Tabela 1, os respondentes percebem a justiça organizacional de forma moderada, pois as médias concentraram-se em torno de 5 que, na escala, corresponde "a concordo ligeiramente". Porém, essa percepção não é homogênea em todas as dimensões, visto que o coeficiente de variação é maior que $30 \%$ em algumas delas. A justiça interpessoal obteve a maior média e o menor coeficiente de variação. Isso denota que os superiores possuem bom relacionamento com seus subordinados, o que eleva as percepções de justiça interpessoal. Consonante a isso, a satisfação com a chefia foi a que apresentou média mais elevada entre as dimensões da satisfação no trabalho. Rego e Souto (2004) também encontraram maior percepção de justiça interpessoal entre empregados de empresas públicas e privadas.

A justiça distributiva de tarefas apresentou a segunda melhor média $(5,38)$ entre as dimensões da justiça organizacional, com coeficiente de variação menor que 30\%. Isso sugere que a percepção de justiça nesta dimensão é homogênea; o mesmo não ocorreu com a justiça distributiva das recompensas, que apresentou a menor média entre as dimensões da justiça. Porém, esta dimensão apresentou o maior coeficiente de variação entre as variáveis de justiça, o que revela grande discrepância entre as respostas.

As médias da justiça informacional e processual foram, respectivamente, 5,02 e 4,79, porém, em ambas as dimensões, o coeficiente de variação foi superior a $30 \%$, o que sugere não homogeneidade entre as respostas. A média aqui encontrada para a dimensão processual foi próxima a encontrada por Nadiri e Tanova (2010) entre funcionários de hotéis, de 3,69 em uma escala de 5 pontos.

No que concerne à satisfação, os níveis em todas as dimensões apresentaram-se moderados. Destacam-se negativamente as dimensões de satisfação com o salário e as promoções - ambas apresentaram médias próximas a 4, o ponto central da escala, o que não denota satisfação nem insatisfação. Todavia, deve-se observar que essas duas dimensões apresentaram elevados coeficientes de variação, o que indica baixos níveis de uniformidade entre as respostas. Por outro lado, assim como a satisfação com a chefia, a satisfação com os colegas de trabalho e a natureza do trabalho apresentaram níveis razoavelmente altos, com coeficientes de variação inferiores a 30\%, o que revela convergência entre as respostas. 
Ao analisar os máximos e mínimos, percebe-se que toda a escala foi utilizada pelos respondentes, pois houve respostas nas duas extremidades. Isso demonstra que enquanto alguns respondentes apresentaram altos escores de satisfação e percepção de justiça, representados aqui pelo máximo 7 , outros apresentaram baixas percepções de justiça e satisfação, representados pelo mínimo 1. De modo geral, há indícios de sentimentos de injustiça e insatisfação em relação à remuneração, promoções e procedimentos organizacionais, o que implica mudanças nas prestadoras de serviços contábeis, principalmente no que concerne às práticas de promoções.

\subsection{Correlações entre as dimensões de justiça com satisfação no trabalho}

$\mathrm{Na}$ Tabela 2, evidenciam-se as correlações de Pearson entre as variáveis analisadas. Correlacionaram-se as cinco dimensões de justiça com as cinco dimensões de satisfação no trabalho. Além disso, fez-se uma média de todas as variáveis de satisfação para obter um escore denominado de satisfação geral, o qual também foi relacionado com cada dimensão de justiça organizacional.

Tabela 2

\section{Correlações de Pearson entre as variáveis}

\begin{tabular}{|c|c|c|c|c|c|c|c|c|c|c|c|}
\hline Variáveis & JD & $J P$ & JINT & JINF & JDT & SS & SCO & SCH & SP & SN & SG \\
\hline $\begin{array}{l}\text { Justiça } \\
\text { distributiva (JD) }\end{array}$ & 1 & & & & & & & & & & \\
\hline $\begin{array}{l}\text { Justiça } \\
\text { processual (JP) }\end{array}$ & $0,852 * *$ & 1 & & & & & & & & & \\
\hline $\begin{array}{l}\text { Justiça } \\
\text { interacional } \\
\text { interpessoal } \\
\text { (JINT) }\end{array}$ & $0,701 * \star$ & $0,823 * *$ & 1 & & & & & & & & \\
\hline $\begin{array}{l}\text { Justiça } \\
\text { interacional } \\
\text { informacional } \\
\text { (JINF) }\end{array}$ & $0,759 * *$ & $0,900 * *$ & $0,875^{\star *}$ & 1 & & & & & & & \\
\hline $\begin{array}{l}\text { Justiça } \\
\text { distributiva das } \\
\text { tarefas (JDT) }\end{array}$ & $0,705 * \star$ & $0,805^{\star \star}$ & $0,736 * *$ & $0,756 * \star$ & 1 & & & & & & \\
\hline $\begin{array}{l}\text { Satisfação com o } \\
\text { salário (SS) }\end{array}$ & $0,889 * \star$ & $0,758 * *$ & $0,672 * *$ & $0,690 * \star$ & $0,636 * *$ & 1 & & & & & \\
\hline $\begin{array}{l}\text { Satisfação com } \\
\text { os colegas (SCOL) }\end{array}$ & $0,243 * \star$ & $0,393^{\star *}$ & $0,404 * *$ & $0,370 * *$ & $0,429 * *$ & $0,326 * *$ & 1 & & & & \\
\hline $\begin{array}{l}\text { Satisfação com a } \\
\text { chefia }(\mathrm{SCH})\end{array}$ & $0,633^{* *}$ & $0,717^{* *}$ & $0,819 * *$ & $0,732^{\star *}$ & $0,662^{* *}$ & $0,652^{* *}$ & $0,478 * *$ & 1 & & & \\
\hline $\begin{array}{l}\text { Satisfação com } \\
\text { as promoções } \\
\text { (SP) }\end{array}$ & $0,726 * \star$ & $0,783^{\star \star}$ & $0,679 * *$ & $0,702^{\star \star}$ & $0,647 * *$ & $0,761 * \star$ & $0,388 * *$ & $0,574 * *$ & 1 & & \\
\hline $\begin{array}{l}\text { Satisfação com } \\
\text { a natureza do } \\
\text { trabalho (SN) }\end{array}$ & $0,618 * *$ & $0,714^{\star \star}$ & $0,667 * *$ & $0,686 * \star$ & $0,710 * *$ & $0,664^{\star \star}$ & $0,545^{\star \star}$ & $0,651 * *$ & $0,711^{* *}$ & 1 & \\
\hline $\begin{array}{l}\text { Satisfação Geral } \\
\text { (SG) }\end{array}$ & $0,799 * *$ & $0,844 * *$ & $0,801 * *$ & $0,791 * *$ & $0,758 * *$ & $0,871 * *$ & $0,619 * \star$ & $0,813 * *$ & $0,880 * *$ & $0,860 * *$ & 1 \\
\hline
\end{tabular}

** $p<0,01$.

Fonte: dados da pesquisa. 
$\mathrm{Na}$ Tabela 2, verifica-se que todas as variáveis da pesquisa estão relacionadas entre si, ao nível de significância menor que $1 \%$, sendo que todas as dimensões de justiça organizacional apresentaram forte correlação positiva entre si. Esses resultados convergem com as pesquisas de Colquit et al. (2001), Rego (2002), Souto e Rego (2003), Rego e Souto (2004) e Sotomayor (2007). Estas correlações, conforme Rego (2002), assentam uma dificuldade metodológica e psicométrica - a (não) independência das dimensões da justiça organizacional.

Diferente dos resultados encontrados por Souto e Rego (2003) e Rego e Souto (2004), em que a associação mais forte ocorreu entre as dimensões interpessoal e informacional, nesse estudo verificou-se que a correlação mais forte foi entre as dimensões processual e informacional. Todavia, a correlação entre a justiça interpessoal e informacional apresentou-se como a segunda associação mais forte. Esses resultados podem explicar o fato de alguns pesquisadores, como, por exemplo, Aryee, Budhwar e Chen (2002), Goldman (2003), Nadiri e Tanova (2010) e Ahmadi et al. (2012), não considerarem a justiça interpessoal e informacional como dimensões distintas, considerando-as como interacional.

No entanto, as dimensões da justiça interacional apresentaram-se mais correlacionadas à justiça processual do que à justiça distributiva. Este fato pode explicar a compreensão de autores, como McFarlin e Sweeney (1992), que entendem a justiça interacional como uma ramificação da justiça processual e, não, uma dimensão independente. Por esse motivo, tais autores consideram apenas duas dimensões: a distributiva e a processual.

Ressalta-se que também foi encontrada forte correlação entre a justiça distributiva e a justiça processual. Esse resultado converge com os estudos de Sweeney e McFarlin (1997), que também identificaram forte correlação entre essas duas dimensões. De forma semelhante, outros autores, como McFarlin e Sweeny (1992), Aryee, Budhwar e Chen (2002) e Ahmadi et al. (2012), encontraram correlação moderada entre a justiça distributiva e a justiça processual.

$\mathrm{Na}$ correlação bivariada entre as dimensões de justiça organizacional e satisfação no trabalho, todas as dimensões da justiça apresentaram-se fortemente correlacionadas à satisfação. Esse resultado suporta a hipótese $\mathrm{H} 1$ que percepções de justiça distributiva, processual, interpessoal, informacional e de tarefas estão positivamente relacionadas com a satisfação no trabalho. Converge ainda com os resultados de McFarlin e Sweeney (1992), Martin e Bennet (1996), Colquitt et al. (2001), Choi (2011), Ahmadi et al. (2012) e Dal Vesco, Popik e Beuren (2016), que encontraram relação positiva entre as dimensões de justiça abordadas em seus estudos e a satisfação no trabalho. Dessa forma, quanto maior o sentimento de justiça nas atividades laborais, maior será sua satisfação com o trabalho.

A dimensão da justiça organizacional que mostrou associação mais forte com a satisfação no trabalho, diferente do esperado, foi a justiça processual, o que leva à rejeição da hipótese $\mathrm{H} 2$, que a percepção de justiça distributiva está mais fortemente relacionada à satisfação no trabalho do que as demais dimensões da justiça organizacional. Esse resultado diverge do encontrado por McFarlin e Sweeney (1992), Martin e Bennet (1996), Choi (2011) e Firoozi, Kazemi e Sayadi (2017) e converge com o resultado de Alexander e Ruderman (1987) e Warner, Reynolds e Roman (2005). Infere-se que os respondentes atribuíram maior ênfase aos procedimentos empregados na distribuição das recompensas e, não, na recompensa propriamente dita. Esse resultado coaduna com a pesquisa de Chetty e Neeraja (2017), em que a justiça processual foi a dimensão de justiça avaliada como mais relevante por funcionários de uma empresa desenvolvedora de softwares.

Ao analisar-se as dimensões da satisfação no trabalho individualmente, percebe-se que, como demonstrado na literatura, diferentes dimensões de justiça correlacionam-se mais fortemente com determinadas dimensões da satisfação. Nesse sentido, na análise das médias, a justiça interpessoal mostrou-se mais fortemente associada à satisfação com a chefia, ou seja, quanto mais justo é o tratamento dispensado pelo superior ao seu subordinado, maior será a satisfação deste para com o superior. 
A justiça distributiva, conforme esperado, correlacionou-se mais fortemente à satisfação com o salário e com as promoções. Esse resultado coaduna com a pesquisa de DeConinck e Stilwell (2004) e indica que quanto maior a percepção de que as recompensas recebidas são justas, maior será a satisfação com tais recompensas. A justiça processual também apresentou forte correlação na satisfação com o salário e com as promoções, o que enseja dizer que não apenas a justiça das recompensas recebidas, mas também a justiça percebida no processo de distribuição, são determinantes para a satisfação com as recompensas, conforme preconizado por Leventhal (1980).

A justiça informacional mostrou-se fortemente relacionada à satisfação com a chefia e moderadamente relacionada à satisfação com o salário e a natureza do trabalho. A justiça distributiva das tarefas revelou-se mais fortemente relacionada à satisfação com a natureza do trabalho. Tal resultado já era esperado, visto as definições teóricas de ambas as variáveis. Por fim, nenhuma das dimensões de justiça organizacional demonstrou-se fortemente associada à satisfação com os colegas. As relações encontradas foram moderadas, para as dimensões interacional e de distribuição de tarefas, enquanto as demais dimensões da justiça apontaram fraca relação com a satisfação com os colegas. Dessa forma, a relação dos sentimentos de justiça com a satisfação no trabalho refere-se aos aspectos organizacionais (recompensas, processos e tarefas) e interação entre chefia e subordinados, mas sem efeitos significativos da interação com colegas de trabalho.

Pesquisadores deram menos atenção à justiça interacional, conforme apontado por López-Cabarcos, Pinho e Rodríguez (2015), mas os resultados dessa pesquisa apontam que as percepções de justiça processual e interacional foram as maiores preditoras da satisfação no trabalho em geral, em detrimento da justiça distributiva. Isso sinaliza que os respondentes podem estar envolvidos em dois tipos de troca: com o seu supervisor e com a organização.

\subsection{Variáveis de controle e percepções de justiça e satisfação no trabalho}

De maneira complementar, foram utilizados os testes de Mann-Whitney e de Kruskal-Wallis para avaliar se as características de gênero, idade, tempo de empresa, existência de metas de trabalho e a adoção da sistemática de remuneração variável implicam diferenças significativas de percepções de justiça e satisfação no trabalho. Nesses testes, se o nível de significância for igual ou menor a 0,05 , indicará que há diferenças entre os grupos analisados.

Tabela 3

Testes de Mann-Whitney e Kruskal-Wallis

\begin{tabular}{lccccc}
\hline \multirow{2}{*}{ Variáveis } & \multicolumn{3}{c}{ Teste de Mann-Whitney } & \multicolumn{2}{c}{ Teste de Kruskal-Wallis } \\
\cline { 2 - 6 } & Gênero & Metas & Remuneração Variável & Idade & Tempo de empresa \\
\hline Justiça distributiva & 0,976 & 0,588 & 0,085 & 0,860 & 0,672 \\
\hline Justiça processual & 0,635 & 0,085 & 0,003 & 0,878 & 0,604 \\
\hline Justiça interacional interpessoal & 0,429 & 0,138 & 0,008 & 0,999 & 0,476 \\
\hline Justiça interacional informacional & 0,963 & 0,058 & 0,002 & 0,725 & 0,597 \\
\hline Justiça distributiva das tarefas & 0,178 & 0,063 & 0,013 & 0,684 & 0,520 \\
\hline Satisfação com o salário & 0,766 & 0,381 & 0,072 & 0,313 & 0,895 \\
\hline Satisfação com os colegas & 0,544 & 0,113 & 0,899 & 0,836 & 0,087 \\
\hline Satisfação com a chefia & 0,902 & 0,099 & 0,290 & 0,903 & 0,643 \\
\hline Satisfação com as promoções & 0,863 & 0,089 & 0,040 & 0,926 & 0,473 \\
\hline Satisfação com a natureza do trabalho & 0,850 & 0,010 & 0,036 & 0,988 & 0,107 \\
\hline
\end{tabular}

Fonte: dados da pesquisa. 
Os resultados do teste de Mann-Whitney denotam que não há diferença de percepção de justiça e satisfação entre homens e mulheres, visto que, para nenhuma das variáveis, houve significância menor que 0,05. Esse resultado diverge da pesquisa de Sweeney e McFarlin (1997), que as mulheres tendem a dar maior ênfase à justiça dos processos do que aos resultados, enquanto os homens mostraram mais forte ênfase na justiça distributiva. Porém, converge com os resultados de Cohen-Charash e Spector (2001), que independente da idade, sexo, raça, escolaridade e posses, as pessoas tendem a perceber a justiça de forma semelhante.

Em relação às metas, apenas satisfação com a natureza do trabalho apresentou grau de significância menor que 0,05 . Isso indica que o grupo que possui metas apresenta níveis de satisfação com a natureza do trabalho diferente daqueles que não possuem metas.

Quanto à remuneração variável, o grupo que recebe algum tipo de remuneração variável percepciona quatro dimensões da justiça organizacional (processual, interacional, informacional e distributiva das tarefas) de forma distinta daqueles que não recebem remuneração variável. Esta distinção de opinião também é observada nos níveis de satisfação com as promoções e satisfação com a natureza do trabalho. As médias dos grupos mostram que aqueles que recebem algum tipo de remuneração variável sentem-se mais justiçados e satisfeitos em comparação àqueles que não recebem remuneração variável.

Tais resultados sinalizam que ter metas não modifica o sentimento de justiça, no entanto, a sistemática de remuneração variável pode ser um indicador para fortalecer tais sentimentos e, consequentemente, reforçar a satisfação no trabalho, o que diverge dos resultados de Odelius e Santos (2008), que não observaram diferenças nas percepções de justiça entre empregados que recebem somente remuneração fixa e aqueles que recebem remuneração variável.

Os resultados do teste de Kruskal-Wallis indicam que não há diferença de percepção de justiça organizacional e de satisfação no trabalho entre as diferentes faixas etárias dos respondestes e entre o seu tempo de empresa, visto que, para nenhuma das variáveis analisadas, observou-se significância menor que 5\%. Esse resultado coaduna com a pesquisa de Cohen-Charash e Spector (2001), que também não identificaram diferença de percepção de justiça em função da idade dos respondentes.

\section{Considerações Finais}

Nessa pesquisa, objetivou-se verificar a relação da percepção de justiça distributiva de recompensas, distributiva de tarefas, processual, interpessoal e informacional com a satisfação no trabalho. Os resultados mostraram que todas as dimensões de justiça organizacional apresentaram forte correlação positiva entre si, o que converge com os resultados de Colquit et al. (2001), Rego (2002), Souto e Rego (2003), Rego e Souto (2004) e Sotomayor (2007). Essa constatação chama a atenção para uma dificuldade relatada na literatura, a (não) independência das dimensões da justiça organizacional.

Os escores baixos de justiça organizacional apontados por alguns respondentes, denotam pouca percepção de justiça no ambiente de trabalho, em todas a dimensões observadas (distributiva de recompensas, distributiva de tarefas, processual, interpessoal e informacional). Este fato também pode explicar os baixos escores de satisfação no trabalho observados entre os indivíduos da amostra, o que sugere que o aumento na percepção de justiça organizacional pode trazer um aumento no nível de satisfação e, consequentemente, no desempenho.

$\mathrm{Na}$ análise das correlações, observou-se que todas as dimensões de justiça organizacional apresentaram forte correlação positiva com satisfação no trabalho, o que converge com os resultados de McFarlin e Sweeney (1992), Martin e Bennet (1996), Colquitt et al. (2001), Choi (2011), Ahmadi et al. (2012) e Dal Vesco, Popik e Beuren (2016), e implica a não rejeição da hipótese H1, de que as percepções de justiça distributiva, processual, interpessoal, informacional e de tarefas estão positivamente relacionadas com a satisfação no trabalho. 
Em relação à hipótese $\mathrm{H} 2$, os resultados apontaram que a justiça processual possui correlação mais forte com a satisfação no trabalho. Esse resultado fornece evidências para a rejeição da $\mathrm{H} 2$, de que a justiça distributiva está mais fortemente relacionada à satisfação no trabalho do que as demais dimensões da justiça organizacional. Esse resultado coaduna com o das pesquisas de Alexander e Ruderman (1987) e Warner, Reynolds e Roman (2005).

Na relação entre as diferentes dimensões da justiça organizacional e da satisfação no trabalho, observou-se que, alinhado ao estudo de DeConinck e Stilwell (2004), a justiça distributiva mostrou-se mais fortemente relacionada à satisfação com o pagamento e as promoções. Também identificou-se forte relação destas dimensões da satisfação com a justiça processual. Argumenta-se que não apenas as recompensas são consideradas, mas também o processo pelo qual essas recompensas são distribuídas. A justiça interacional e a informacional apresentaram-se mais fortemente associadas à satisfação com a chefia, $o$ que indica que um tratamento justo e o fornecimento de explicações sobre os procedimentos e decisões contribuem para o nível de satisfação do subordinado com seu superior.

Os testes de Mann-Whitney e Kruskal-Wallis revelaram que a percepção de justiça e o nível de satisfação são independentes do gênero, idade e tempo de empresa dos respondentes. Em relação ao estabelecimento de metas, observou-se que este procedimento não suscita maiores sentimentos de justiça, nem impacta na satisfação do trabalho como um todo. Por outro lado, a sistemática de remuneração variável é um elemento que interfere nos sentimentos de justiça e, consequentemente, em maior satisfação no trabalho. Desse modo, o estabelecimento de metas deve vir acompanhado da prática de remuneração variável, caso se almeje maior sentimento de justiça.

Ressalta-se, no entanto, que os resultados apresentados restringem-se à amostra analisada. Destaca-se ainda como limitações da pesquisa, as técnicas estatísticas empregadas na análise dos dados e a quantidade de dimensões de justiça organizacional utilizadas, visto que, como enfatizado na revisão de literatura, não há consenso quanto ao número de dimensões que constituem o construto da justiça organizacional. Como sugestões para futuras pesquisas, recomenda-se a investigação do impacto das percepções de justiça organizacional e da satisfação no trabalho sobre o comprometimento e o desempenho dos funcionários. Outra pesquisa pode ater-se aos antecedentes das percepções de justiça.

\section{Referências}

Adams, J.S. (1965). Inequity in social exchange. Advances in Experimental Social Psychology, 2, pp. 267 299). New York: Academic Press. doi: https://doi.org/10.1016/S0065-2601(08)60108-2

Ahmadi, S.A.A., Daraei, M.R., Rabiei, H., \& Takallo, Y.S.H. (2012). The study on relationship between organizational justice, organizational citizenship behaviour, job satisfaction and turnover intentions a comparison between public sector and private sector. International Business Management, 6(1), pp. 22-31. doi: 10.3923/ibm.2012.22.31

Alexander, S., \& Ruderman, M. (1987). The role of procedural and distributive justice in organizational behavior. Social Justice Research, 1(2), pp. 177-198. doi: https://doi.org/10.1007/BF01048015

Aryee, S., Budhwar, P.S., \& Chen, Z.X. (2002). Trust as a mediator of the relationship between organizational justice and work outcomes: test of a social exchange model. Journal of Organizational Behavior, 23(3), pp. 267-285. doi: 10.1002/job.138

Assmar, E.M.L., Ferreira, M.C., \& Souto, S.D.O. (2005). Justiça organizacional: uma revisão crítica da literatura. Psicologia: Reflexão e Crítica, 18(3), pp. 443-453. doi: http://dx.doi.org/10.1590/S010279722005000300019 
Beuren, I.M., Klein, L., Lara, F.L., \& Almeida, L.B. (2016). Percepção de justiça nos sistemas de controle gerencial aumenta comprometimento e confiança dos gestores? Revista de Administração Contemporânea, 20(2), pp. 216-237. doi: http://dx.doi.org/10.1590/1982-7849rac2016140083

Bies, R.J., \& Moag, J.S. (1986). Interactional justice communication criteria of fairness. Research on Negotiation in Organizations, 1(1), pp. 43-55.

Chetty, K., \& Neeraja, B. (2017). A study on impact of organizational justice perception on job satisfaction: Indian software employees' perspective. International Journal of Applied Business and Economic Research, 15(4), pp. 387-399.

Choi, S. (2011). Organizational justice and employee work attitudes: The federal case. The American Review of Public Administration, 41(2), pp. 185-204. doi: 10.1177/0275074010373275

Cohen-Charash, Y., \& Spector, P.E. (2001). The role of justice in organizations: a meta analysis. Organizational Behavior and Human Decision Processes, 86(2), pp. 278-321. doi: https:/doi.org/10.1006/ obhd.2001.2958

Colquitt, J.A. (2001). On the dimensionality of organizational justice: A construct validation of a measure. Journal of Applied Psychology, 86(3), pp. 386-400. doi: 10.1037//0021-9010.86.3.386

Colquitt, J.A., Conlon, D.E., Wesson, M.J., Porter, C.O.L.H., \& Ng, K.Y. (2001). Justice at the millennium: A meta-analytic review of 25 years of organizational justice research. Journal of Applied Psychology, 86(3), pp. 425-445. doi: 10.1037//0021-9010.86.3.425

Dal Vesco, D.G., Beuren, I.M., \& Popik, F. (2016). Percepção de justiça na avaliação na avaliação de desempenho e satisfação do trabalho. Enfoque: Reflexão Contábil, 35(3), pp. 121-138. doi: http://dx.doi. org/10.4025/enfoque.v35i3.28333

DeConinck, J.B., \& Stilwell, C.D. (2004). Incorporating organizational justice, role states, pay satisfaction and supervisor satisfaction in a model of turnover intentions. Journal of Business Research, 57(3), pp. 225-231. doi: https://doi.org/10.1016/S0148-2963(02)00289-8

Firoozi, M., Kazemi, A., \& Sayadi, N. (2017). A Study of the Relationship between the Components of Organizational Justice and the Dimensions of Job Satisfaction of Physical Education Teachers. Pertanika Journal of Social Science and Humanities, 25(2), pp. 541-551.

Goldman, B.M. (2003). The application of referent cognitions theory to legal-claiming by terminated workers: The role of organizational justice and anger. Journal of Management, 29(5), pp. 705-728. doi: https://doi.org/10.1016/S0149-2063(03)00032-1

Greenberg, J. (1987). Reactions to procedural injustice in payment distributions: Do the means justify the ends? Journal of Applied Psychology, 72(1), pp. 55-61. doi: http://dx.doi.org/10.1037/00219010.72.1.55

Greenberg, J. (1993a). The social side of fairness: interpersonal and informational classes of organizational justice. In: Cropanzano, R. (Org.). Justice in the workplace: approaching fairness in human resource management. Hillsdale: Lawrence Erlbaum Associates.

Greenberg, J. (1993b). Justice and organizational citizenship: A commentary on the state of the science. Employee Responsibilities and Rights Journal, 6(3), pp. 249-256. doi: http://dx.doi.org/10.1007/ BF01419448

Klendauer, R., \& Deller, J. (2009). Organizational justice and managerial commitment in corporate mergers. Journal of Managerial Psychology, 24(1), pp. 29-45. doi: https://doi.org/10.1108/02683940910922528

Konovsky, M.A. (2000). Understanding procedural justice and its impact on business organizations. Journal of Management, 26(3), pp. 489-511. doi: https://doi.org/10.1016/S0149-2063(00)00042-8 
Lai Wan, H. (2007). Human capital development policies: enhancing employees' satisfaction. Journal of European Industrial Training, 31(4), pp. 297-322. doi: https://doi.org/10.1108/03090590710746450

Lamertz, K. (2002). The social construction of fairness: Social influence and sense making in organizations. Journal of Organizational Behavior, 23(1), pp. 19-37. doi: 10.1002/job.128

Langevin, P., \& Mendoza, C. (2013). How can management control system fairness reduce managers' unethical behaviours? European Management Journal, 31(3), pp. 209-222. doi: https://doi.org/10.1016/j. emj.2012.12.001

Leventhal, G.S. (1980). What should be done with equity theory? New approaches to the study of fairness in social relationships. US: Springer. doi: https://doi.org/10.1007/978-1-4613-3087-5_2

Locke, E.A. (1969). What is job satisfaction? Organizational Behavior and Human Performance, 4(4), pp. 309-336. doi: https://doi.org/10.1016/0030-5073(69)90013-0

López-Cabarcos, M.A., Machado-Lopes-Sampaio-de Pinho, A.I., \& Vázquez-Rodríguez, P. (2015). The influence of organizational justice and job satisfaction on organizational commitment in Portugal's hotel industry. Cornell Hospitality Quarterly, 56(3), pp. 258-272. doi: 10.1177/1938965514545680

Martin, C. L., \& Bennett, N. (1996). The role of justice judgments in explaining the relationship between job satisfaction and organizational commitment. Group \& Organization Management, 21(1), pp. 84-104. doi: http://dx.doi.org/10.1177/1059601196211005

Martinez, M.C., \& Paraguay, A.I.B.B. (2003). Satisfação e saúde no trabalho: aspectos conceituais e metodológicos. Cadernos de Psicologia Social do Trabalho, 6(1), pp. 59-78. doi: http://dx.doi.org/10.11606/ issn.1981-0490.v6i0p59-78

Masterson, S.S., Lewis, K., Goldman, B.M., \& Taylor, M.S. (2000). Integrating justice and social exchange: The differing effects of fair procedures and treatment on work relationships. Academy of Management Journal, 43(4), pp. 738-748. doi: 10.2307/1556364

McFarlin, D.B., Sweeney, P.D. (1992). Research notes. Distributive and procedural justice as predictors of satisfaction with personal and organizational outcomes. Academy of Management Journal, 35(3), pp. 626-637. doi: 10.2307/256489

Nadiri, H., \& Tanova, C. (2010). An investigation of the role of justice in turnover intentions, job satisfaction, and organizational citizenship behavior in hospitality industry. International Journal of Hospitality Management, 29(1), pp. 33-41. doi: https://doi.org/10.1016/j.ijhm.2009.05.001

Odelius, C.C., \& Rabelo dos Santos, A. (2008). Percepção de justiça organizacional de sistemas de remuneração em organizações públicas. Revista Alcance, 15(2), pp. 226-242.

Omar, A.; Ferreira, M.C.; Souto, S.O.; Delgado, H.U.; Assmar, E.M.L.; González, A.T.; Galáz, M. T. (2007). Colectivismo, justicia y ciudadanía organizacional en empresas argentinas, mexicanas y brasileiras. Revista Mexicana de Psicología, 24(1), pp. 101-116.

Parker, R.J., \& Kohlmeyer, J.M. (2005). Organizational justice and turnover in public accounting firms: a research note. Accounting, Organizations and Society, 30(4), pp. 357-369. doi: https://doi.org/10.1016/j. aos.2004.05.001

Rahim, M.A., Magner, N.R., \& Shapiro, D.L. (2000). Do justice perceptions influence styles of handling conflict with supervisors? What justice perceptions, precisely?. International Journal of Conflict Management, 11(1), pp. 9-31. doi: https://doi.org/10.1108/eb022833

Rego, A. (2000). Percepções de justiça dos professores do ensino superior: desenvolvimento e validação de um instrumento de medida. Linhas Críticas, 6(11), pp. 131-154. 
Rego, A. (2001). Percepções de justiça: estudos de dimensionalização com professores do ensino superior. Psicologia: Teoria e Pesquisa, 17(2), pp. 119-131. doi: http://dx.doi.org/10.1590/S010237722001000200004

Rego, A. (2002). Comprometimento afectivo dos membros organizacionais: o papel das percepções de justiça. Revista de Administração Contemporânea, 6(2), pp. 209-241. doi: http://dx.doi.org/10.1590/ S1415-65552002000200012

Rego, A., \& Souto, S. (2004). A percepção de justiça como antecedente do comprometimento organizacional: um estudo luso-brasileiro. Revista de Administração Contemporânea, 8(1), pp. 151-177. doi: http://dx.doi.org/10.1590/S1415-65552004000100008

Robbins, S.P. (2005). Comportamento organizacional. $11^{\text {a }}$ ed. São Paulo: Prentice Hall.

Rueda, F.J.M., Baptista, M.N., Souza, M.S., Degenhardt, I., \& Nicoletti, I.G. (2010). Escala de Suporte Laboral (ESUL) e escala de satisfação no trabalho: evidências de validade. Avaliação Psicológica, 9(3), pp. $479-488$.

Siqueira, M.M.M. (2008). Satisfação no trabalho. In: Siqueira, M.M.M. (Org.). Medidas do Comportamento Organizacional: ferramentas de diagnóstico e de gestão. Porto Alegre: Armed.

Sotomayor, A.M.S.B. (2007). Avaliação de desempenho e compromisso organizacional: a perspectiva da justiça organizacional. Revista Universo Contábil, 3(3), pp. 87-100.

Souto, S., \& Rego, A. (2003). O modelo tetradimensional da justiça organizacional: uma versão brasileira. Revista de Administração FACES Journal, 2(2), pp. 9-23. doi: http://dx.doi.org/10.21714/1984-6975FACES2003V2N2ART22

Suehiro, A.C.B., Santos, A.A.A.D., Hatamoto, C.T., \& Cardoso, M.M. (2008). Vulnerabilidade ao estresse e satisfação no trabalho em profissionais do programa de saúde da família. Boletim de Psicologia, 58(129), pp. 205-218.

Sweeney, P.D., \& McFarlin, D.B. (1997). Process and outcome: gender differences in the assessment of justice. Journal of Organizational Behavior, 18(1), pp. 83-98. doi: http://dx.doi.org/10.1002/(SICI)1099-1379(199701)18:1<83::AID-JOB779>3.0.CO;2-3

Tepper, B.J. (2001). Health consequences of organizational injustice: Tests of main and interactive effects. Organizational Behavior and Human Decision Processes, 86(2), pp. 197-215. doi: https://doi. org/10.1006/obhd.2001.2951

Thibaut, J.W., \& Walker, L. (1975). Procedural justice: A psychological analysis. Hillsdale: L. Erlbaum Associates.

Warner, J.C., Reynolds, J., \& Roman, P. (2005). Organizational justice and job satisfaction: A test of three competing models. Social Justice Research, 18(4), pp. 391-409. doi: https://doi.org/10.1007/s11211005-8567-5

Zainalipour, H., Fini, A.A.S., \& Mirkamali, S.M. (2010). A study of relationship between organizational justice and job satisfaction among teachers in Bandar Abbas middle school. Procedia: Social and Behavioral Sciences, 5(1), pp. 1986-1990. doi: https://doi.org/10.1016/j.sbspro.2010.07.401 